\title{
CBCT Radiological Features as Predictors of Nerve Injuries in Third Molar Extractions: Multicenter Prospective Study on a Northeastern Italian Population
}

\author{
Stefano Bigagnoli ${ }^{1}$, Christian Greco ${ }^{2}$, Fulvia Costantinides ${ }^{1}$, Davide Porrelli ${ }^{3} \mathbb{D}$, Lorenzo Bevilacqua ${ }^{1, *}(\mathbb{D}$ \\ and Michele Maglione ${ }^{1}$ (D)
}

1 School of Specialization in Oral Surgery, Unit of Oral Surgery, Department of Medical, Surgical and Health Sciences, University of Trieste, Piazza dell'Ospitale 1, 34129 Trieste, Italy; bigagnolistefano@gmail.com (S.B.); F.COSTANTINIDES@fmc.units.it (F.C.); m.maglione@fmc.units.it (M.M.)

2 Unit of Dentistry, Merano Hospital, via Giacomo Rossini 5, 39012 Merano, Italy; christian.greco@asbmeran-o.it

3 Department of Medical, Surgical and Health Sciences, University of Trieste, Piazza dell'Ospitale 1, 34129 Trieste, Italy; dporrelli@units.it

* Correspondence: 1.bevilacqua@fmc.units.it

check for updates

Citation: Bigagnoli, S.; Greco, C.; Costantinides, F.; Porrelli, D.; Bevilacqua, L.; Maglione, M. CBCT Radiological Features as Predictors of Nerve Injuries in Third Molar Extractions: Multicenter Prospective Study on a Northeastern Italian Population. Dent. J. 2021, 9, 23. https://doi.org/10.3390/dj9020023

Academic Editor: Christian Bacci

Received: 18 January 2021

Accepted: 14 February 2021

Published: 21 February 2021

Publisher's Note: MDPI stays neutral with regard to jurisdictional claims in published maps and institutional affiliations.

Copyright: (c) 2021 by the authors. Licensee MDPI, Basel, Switzerland. This article is an open access article distributed under the terms and conditions of the Creative Commons Attribution (CC BY) license (https:/ / creativecommons.org/licenses/by/ $4.0 /)$.

\begin{abstract}
Background: Neurological alterations are one of the main complications occurring after the third molar extractions. The aim of this prospective multicenter cohort study was to find out Cone Beam Computed Tomography (СBCT) features and distribution of neurological complications in patients undergoing lower third molar surgery and to determine the radiological and patientrelated factors that could be correlated to the occurrence of inferior alveolar and lingual nerves injury. Material and Methods: 378 patients who underwent lower third molar extraction from March 2018 to March 2019 were included. Clinical and radiological data were collected. CBCT features were recorded following Maglione et al. classification. Symptoms and characteristics of patients who experienced neurological alterations were evaluated. Results: 193 patients needed a second-level radiological exam (CBCT). In these patients, the most common feature was Maglione class 3: a higher frequency of apical or buccal mandibular canals in direct contact with the tooth was observed. 3.17\% of the patients developed a neurological complication. Maglione class 4, increased age, and operative time were all positively correlated with neurological alterations. Conclusions: while the buccal or apical position of the mandibular canal was the more common findings, the lingual position was found to have a higher correlation with a negative outcome. Age and operative time were also found to be risk factors for developing nerve injury in the considered population.
\end{abstract}

Keywords: CBCT; third molars; classification; nerve injures

\section{Introduction}

Neurological alterations after third molar extractions are one of the main concerns among oral surgeons. Third molars are indeed positioned closely, and sometimes almost in contact, to at least three branches of the mandibular nerve: lingual nerve (LN), inferior alveolar nerve (IAN), and buccal nerve (BN) are sensitive branches that can be involved in a third molar extraction. The spatial relation of the third molar crowns and roots represents a major challenge for the surgeon, who must take care of these important structures in all surgical procedures. An injury to these branches can result in an array of clinical presentations, from a temporary mild numbness of a small area to a permanent great painful discomfort of a wide anatomical region. This is mainly because these nerves can be injured in many ways, from postoperative swelling compression to cutting bur shearing [1].

Preoperative 3D imaging techniques represent a staple in surgery whenever the surgeon has a suspect of an intimate anatomic relationship of the nerve with the surgical 
site [2]. For the determination of LN position, it is possible to take advantage of MRI technologies, although they do not represent a routine first-level imaging technique [3].

LN is found to be closely bound to the lingual cortical plate in 20 to $60 \%$ of cases [4-8] and above the bone crest in a considerable percentage of cases (4.6 to $21 \%)[4,5,7,9]$. It lays behind the retro-molar region in 0.5 to $1.5 \%$ of cases [5,7]. Age and crest atrophy seems to worsen this anatomical relationship [4].

An LN injury gives the greatest discomfort to the patient that often leads to legal consequences [10-13].

Some characteristics and procedures that can have an impact on the frequency of LN injury are reported to be a too distal lingual incision, too apical sutures, advanced age, total inclusion, the distal inclination of the tooth, lingual split techniques and distolingual ostectomy procedures [14-18].

The mandibular canal, where IAN runs parallel with the mandibular artery and vein, has very often an intimate relationship with the third molar root, with frequent modification in caliber, shape and corticalization in correspondence with the tooth.

IAN be accurately visualized through Computed Tomography (CT) or Cone Beam Computed Tomography (CBCT imaging [2], which can provide surgeons important additional information. This information appears to have a positive impact on temporary injury incidence but not on the frequency of permanent alteration [19]. Some authors report an apical or buccal course of the canal to be more prevalent in some populations [20-25]. Other studies report a lingual course to be more common $[16,26]$. Interradicular canals occur in 4 to $15 \%$ of the cases $[20,21,27]$. Several authors report that in most of the cases, IAN is not in direct contact with the tooth [21,22], although other works point out that a 2D radiographic analysis is not appropriate to claim this observation [28-33].

Rood's signs [34] are commonly used as indicators to proceed with a 3D exam because many studies related them with IAN injuries [30,35-37], while others reported neurological complications also without these radiological findings $[15,38]$. Nowadays, also the minimal superimposition of the canal with the tooth structures is considered to be an indicator of the need for a radiographic examination [2].

One of the main issues that can be visualized with 3D radiographs is the absence of corticalization of the mandibular canal that is in contact with the tooth. This finding is considered by many authors as a risk indicator for IAN injury during third molar surgery [24,39-42], while others consider it as a mere anatomical feature not related to neurological sequelae $[2,38,43]$.

An increased risk of IAN injuries was reported when a cowbell or tear shape of the canal in contact with the third molar can be visualized [44]. Furthermore, the lingual position of the mandibular canal is considered a risk indicator for sensitivity alteration by some authors $[20,26,45]$.

A new CBCT classification has been recently proposed by Maglione et al. [22]. Seven different classes were edited accordingly to the relative position between the mandibular canal and third molar as they appear in cross-sectional images of a 3D radiograph: as reported in Table 1.

IAN injuries may vary by the entity of discomfort caused [46,47]. Some factors and procedures, believed to be correlated with a higher risk of IAN injuries, include advanced patient age, with a cutoff value of 25 years, some Rood's signs like root radiotrasparency and deflection in contact with the mandibular canal, intraoperative nerve exposition and lingual split technique application $[15,16,31,48-51]$. In addition, general anesthesia seems to be a variable that increases the risk of neurological disturbances after the third molar removal [52,53].

Buccal nerve (BN) runs buccally to the third molar and can be involved when the distal releasing incision is performed. It provides sensitivity for cheek mucosa (and minimally skin), posterior alveolar mucosa, keratinized gingiva, and it can send some terminal branches to the lower and upper lip [54]. 
Table 1. CBCT Radiological Classification by Maglione, Costantinides, Bazzocchi, 2015.

\begin{tabular}{c} 
Class \\
$\begin{array}{c}\text { Subtype } \\
\text { images (plexiform canal) }\end{array}$ \\
Class O: Mandibular canal is not visible on the \\
Tooth/Inferior Alveolar Nerve (IAN) \\
$\begin{array}{c}\text { Class 1: Mandibular canal runs apically or } \\
\text { buccally with respect to the tooth but without } \\
\text { touching it (the cortical limitations of the canal } \\
\text { are not interrupted) }\end{array}$ \\
\hline
\end{tabular}

2A: IAN-tooth distance is greater than $2 \mathrm{~mm}$

Class 2: Mandibular canal runs lingually with respect to the tooth but without touching it (the cortical limitations of the canal are not interrupted)

2B: IAN-tooth distance is less than $2 \mathrm{~mm}$
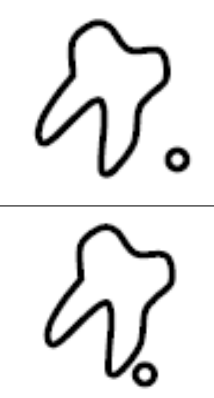
3A: In the point of contact, the mandibular canal shows a preserved diameter

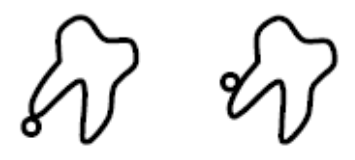

Class 3: Mandibular canal runs apical or buccal, touching the tooth

3B: In the point of contact, the mandibular canal shows a smaller caliber and/or an interruption of the cortication

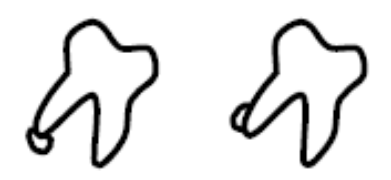

4A: In the point of contact, the mandibular canal shows a preserved diameter

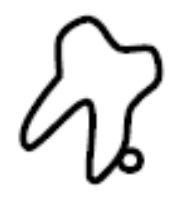

Class 4: Mandibular canal runs lingually, touching the tooth

4B: In the point of contact, the mandibular canal shows a small caliber and/or an interruption of the cortication

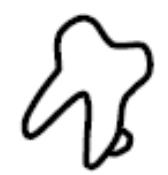


Table 1. Cont.

\begin{tabular}{|c|c|c|}
\hline Class & Subtype & $\begin{array}{l}\text { Scheme of the RELATIONSHIP between } \\
\text { Tooth/Inferior Alveolar Nerve (IAN) }\end{array}$ \\
\hline \multirow{2}{*}{$\begin{array}{l}\text { Class 5: Mandibular canal runs between the } \\
\text { roots but without touching them }\end{array}$} & $\begin{array}{l}\text { 5A: IAN-tooth distance is } \\
\text { greater than } 2 \mathrm{~mm}\end{array}$ & \\
\hline & $\begin{array}{c}\text { 5B: IAN-tooth distance is less } \\
\text { than } 2 \mathrm{~mm}\end{array}$ & \\
\hline \multirow{2}{*}{$\begin{array}{l}\text { Class 6: Mandibular canal runs between the } \\
\text { roots touching them }\end{array}$} & $\begin{array}{l}\text { 6A: In the point of contact, the } \\
\text { mandibular canal shows a } \\
\text { preserved diameter }\end{array}$ & \\
\hline & $\begin{array}{l}\text { 6B: In the point of contact, the } \\
\text { mandibular canal shows a small } \\
\text { caliber and/or an interruption } \\
\text { of the } \\
\text { cortication }\end{array}$ & \\
\hline $\begin{array}{l}\text { Class 7: Mandibular canal runs between fused } \\
\text { roots }\end{array}$ & & \\
\hline
\end{tabular}

However, this is the least investigated structure because its damage has a mild clinical presentation due to conspicuous nerve overlapping in the area [55].

Some authors report a postoperative injury rate that is comparable with the other two branches [56]. Nowadays, the incidence of NL damages seems to be comprised between $0.1 \%$ and $22 \%$, while the incidence of IAN injuries during third molar surgery is attested between $0.17 \%$ and $8.4 \%$ [15].

Some authors report widely higher rates in difficult cases when an anatomical continuity between the canal and the tooth is assessed $[57,58]$.

If sensitive disturbances last more than nine months, with an important cutoff at six months, nerve damage must be considered permanent [1,46,47]. According to various papers, IAN lesions do not recover in a percentage comprised between $0.04 \%$ and $0.7 \%$ of cases [12,16,59]. LN lesions become permanent in about $1 \%$ of cases $[16,49]$. In order to prevent LN lesion, it seems safe to preoperatively verify the integrity of the lingual cortex, avoiding forces that could break it and, in case of a lingual tilted crown, to perform a horizontal coronectomy in the mesial-distal direction [60-62]. If a lingual flap must be elevated, it must be protected with wide and rounded-edge retractors $[14,63,64]$. It is also mandatory to avoid a too-apical suture $[46,60]$.

In order to minimize IAN injury risk, it seems safe to achieve good surgical access, performing a conservative ostectomy, especially on the distal-lingual side, avoiding high elevation forces using conscious tooth sectioning, and avoiding vigorous socket cleaning [60].

The principal aim of this study was to analyze the distribution of Maglione et al. classification in a population at risk of neurological disturbance after third molar removal. The second aim was to find out if any correlation exists between one of these classes and 
other perioperative factors with the development of neurological complications in a cohort of Italian patients who underwent third molar extraction.

\section{Materials and Methods}

In this prospective multicenter cohort study, clinical data of 378 consecutive patients who underwent lower third molar extraction were collected over a 1-year time lap (from March 2018 to March 2019).

A total of 212 of these patients were evaluated and treated at the Unit of Oral Surgery, University of Trieste, (Trieste, Italy), whereas 166 were treated at the Dental Service of Merano Hospital (Merano, Bolzano, Italy).

The study was approved by the local ethical committee (UNITS 7/2016). Informed written consent was obtained from each patient to use clinical data for the research that was conducted in agreement with the guidelines of the Helsinki Declaration as revised in 1975 and amended in October 2003. All patients signed an informed consent regarding surgery approval. All surgeries were performed in a standardized fashion, using the same surgical and pharmacological protocols. All surgeons had at least 5 years of experience in third molar removal.

All patients underwent a first level 2D radiological examination (orthopantomography or intraoral X-ray), and if a contiguity relationship between mandibular canal and tooth was suspected, a CBCT was performed, following evidence-based indications of SEDENTEXCT project of the Europe EC, European Commission (2012) [65].

Before surgery, the patient performed a mouth rinse of chlorhexidine $0.12 \%$ for one minute. Antibiotic prophylaxis was administered only when there was a risk for infective endocarditis, following the indications of American Heart Association's guidelines, or for other systemic pathologies related to bacteremia [66].

Surgery was performed under local or general anesthesia. Anyway, 3\% mepivacaine with epinephrine 1:100.000 for IAN and NL block plus local infiltration was injected. All sutures were nonabsorbable silk 3.0 that was removed after a week.

After surgery, all patients were administered antibiotic therapy, with amoxicillin $1 \mathrm{~g}$ TID for 5 days and an antalgic therapy, with acetaminophen $1000 \mathrm{mg}$ BID for 3 days.

The same operators (S.B. and C.G.) carefully filled in a data collection form for each patient at the end of the intervention. These forms were temporarily stored in a locked facility inside the operative unit. For every patient, a progressive number code was assigned for identification. The following items were collected: gender, date of birth, tooth extracted, presence of CBCT images, Winter and Pell and Gregory (P\&G) classification of the tooth, Maglione et al. radiological class [22] (for CBCT only), surgical procedures like flap elevation, osteotomy procedures, tooth sectioning, anesthesia type, operative time (measured from incision to socket cleaning).

Patients were then seen after 7 days for the suture removal and were asked to report any postoperative sensitivity disturbances. In case of a positive answer, the following points were investigated: nerve branch injured, disturbance type, symptoms experienced, an anatomic extension of the sensitivity impairment. Tablets of Alanerv ${ }^{\circledR} 920$ mg (Alfa Wassermann Spa, Italy) BID for 2 weeks were administered. Then, patients were followedup every 2 weeks for signs and symptoms monitoring until their resolution. After 6 months without recovery, the neurological complication was considered permanent.

\section{Statistical Analysis}

After the study expected term (1 year), data were gathered from collection forms and put in a spreadsheet (Microsoft Excel, Microsoft Corporation, Redmond, WA, USA). Statistical analysis was performed with the same software.

A $t$-test and Fisher's exact test were used to assess any difference in sample characteristics between the CBCT patient group and no CBCT group. These tests were also used to evaluate differences between the contact group and no contact group in the CBCT sample. The test was considered significant if $\alpha$ was $<0.05$. 
A chi-squared test was used to evaluate variables distribution inside two populations: patients who suffered a postoperative neurological complication vs. patients who did not. A chi-squared test was also used to analyze the Maglione et al. radiological classes among genders. The test was considered significant if $\alpha$ was $<0.05$. An ANOVA test with Tukey's post hoc test was used to analyze the distribution of ages among the Maglione et al. radiological classes.

\section{Results}

The characteristics of patients divided into two groups (those who needed CBCT examination and those who did not) are reported in Table 2.

Table 2. Characteristics of patients with Cone Beam Computed Tomography (CBCT) vs. patients with 2D X-rays only (Orthopantomography, OPT).

\begin{tabular}{|c|c|c|c|}
\hline & СВCT $(n=193)$ & No CBCT ( $n=185)$ & $p$ Value \\
\hline $\begin{array}{l}\text { Age mean } \pm \text { SD } \\
\text { Gender } \boldsymbol{n}(\%)\end{array}$ & \multicolumn{2}{|c|}{ Gender $n(\%)$} & $\mathrm{NS}^{\mathrm{a}}$ \\
\hline Males & $94(48.7 \%)$ & $108(58.4 \%)$ & $\mathrm{NS}^{\mathrm{b}}$ \\
\hline Females & $99(51.3 \%)$ & $77(41.6 \%) *$ & $\mathrm{NS}{ }^{b}$ \\
\hline \multicolumn{4}{|l|}{ Pell and Gregory } \\
\hline \multicolumn{4}{|l|}{ Classification, $n(\%)$} \\
\hline $1-\mathrm{A}$ & $14(7.25 \%)$ & $42(22.7 \%)$ & $<0.05^{\mathrm{b}}$ \\
\hline $1-B$ & $15(7.77 \%)$ & $20(10.81 \%)$ & $<0.05^{b}$ \\
\hline $1-\mathrm{C}$ & $6(3.1 \%)$ & $5(2.7 \%)$ & $\mathrm{NS}^{\mathrm{b}}$ \\
\hline $2-\mathrm{A}$ & $19(9.84 \%)$ & $30(16.21 \%)$ & $<0.05^{b}$ \\
\hline $2-B$ & $79(40.93 \%)$ & $56(30.27 \%)$ & $<0.05^{\mathrm{b}}$ \\
\hline $2-C$ & $34(17.61 \%)$ & $14(7.56 \%)$ & $<0.05^{b}$ \\
\hline 3-A & $1(0.52 \%)$ & $1(0.54 \%)$ & $\mathrm{NS}^{\mathrm{b}}$ \\
\hline $3-B$ & $8(4.14 \%)$ & $7(3.78 \%)$ & NS ${ }^{b}$ \\
\hline $3-\mathrm{C}$ & $17(8.81 \%)$ & $10(5.4 \%)$ & $<0.05^{b}$ \\
\hline \multicolumn{4}{|l|}{ Surgical Technique, $n(\%)$} \\
\hline Simple extraction & $1(0.52 \%)$ & $16(8.29 \%)$ & $<0.001^{b}$ \\
\hline Flap & $192(99.48 \%)$ & $177(91.71 \%)$ & $\mathrm{NS}^{\mathrm{b}}$ \\
\hline Ostectomy & $187(96.89 \%)$ & $166(86.01 \%)$ & $\mathrm{NS}^{\mathrm{b}}$ \\
\hline Tooth sectioning & $173(89.63 \%)$ & $135(69.95 \%)$ & $<0.05^{\mathrm{b}}$ \\
\hline \multicolumn{4}{|l|}{ Indication for extraction } \\
\hline Orthodontic & $8(4.14 \%)$ & $9(4.96 \%)$ & $\mathrm{NS}^{\mathrm{b}}$ \\
\hline Pericoronitis & $104(53.88 \%)$ & $100(54.05 \%)$ & NS ${ }^{b}$ \\
\hline Caries of the third molar & $17(8.81 \%)$ & $38(20.54 \%)$ & $<0.05^{b}$ \\
\hline Caries of second molar & $6(3.11 \%)$ & $3(1.62 \%)$ & $<0.05^{\mathrm{b}}$ \\
\hline Prosthetic reasons & $1(0.52 \%)$ & $0(0 \%)$ & - \\
\hline Periodontitis of second molar & $38(19.69 \%)$ & $16(8.64 \%)$ & $<0.05^{b}$ \\
\hline Cyst & $6(3.11 \%)$ & $3(1.62 \%)$ & $<0.05^{b}$ \\
\hline Oncological reasons & $1(0.52 \%)$ & $0(0 \%)$ & - \\
\hline Mandibular fracture & $1(0.52 \%)$ & $0(0 \%)$ & - \\
\hline IAN neuritis & $1(0.52 \%)$ & $0(0 \%)$ & - \\
\hline Abscess & $1(0.52 \%)$ & $0(0 \%)$ & - \\
\hline No pathology & $9(4.66 \%)$ & $16(8.64 \%)$ & $<0.05^{b}$ \\
\hline
\end{tabular}

$\mathrm{SD}$, standard deviation; ${ }^{\mathrm{a}} t$-test; ${ }^{\mathrm{b}}$ Fisher's exact test; ${ }^{*}$ significant difference between the groups $(p<0.05)$.

In the sample of 378 patients, 207 were female (54.76\%) and 171 male $(45.23 \%)$. The average age was $29.38( \pm 11.97)$ with a range between 13 and 83 years. Patients were equally distributed in terms of gender and age (differences in the distributions are not statistically significant) in the two groups (CBCT and No CBCT).

A total of 191 (50.53\%) third mandibular left molars and 187 (49.47\%) third mandibular right molars were extracted.

According to Winter classification, 140 elements (37.04\%) were mesio-inclined, 115 $(30.42 \%)$ were vertical, $67(17.72 \%)$ were horizontal, 33 (8.7\%) teeth were disto-inclined and 
five $(1.32 \%)$ had an eccentric position. For 17 elements $(4.49 \%)$, this information did not emerge clearly. As to the relative depth of the element compared to the second molar (P\&G classification), 106 teeth (28.04\%) lied with the occlusal plane at the level of the second molar (P\&G a), 183 (48.41\%) had the occlusal plane between the CEJ and the occlusal plane of the second molar (P\&G b) and 86 (22.75\%) below the CEJ of the second molar (P\&G c). For three patients $(0.79 \%)$, this information was not clear. A total of 101 elements $(26.72 \%)$ were totally outside the mandibular branch (P\&G 1), 232 (61.37\%) were partially included in the branch (P\&G 2), and 43 (11.37\%) were totally included in the branch (P\&G $3)$. For two elements $(0.53 \%)$, this information was not clear. As expected, The Fisher's test showed that the impaction of the third molars was lower $(1 \mathrm{~A}, 1 \mathrm{~B}, 2 \mathrm{~A})$ for patients in which a CBCT was not required $(p>0.05)$, and higher $(2 B, 2 C, 3 C)$ in those which required a CBCT examination.

A total of 369 interventions (97.6\%) included a flap elevation, 353 (93.3\%) needed ostectomy procedures, and in 308 cases $(81.5 \%)$, a tooth section was performed. Simple extractions were performed mostly $(p<0.001)$ in patients for whom CBCT was not necessary, while tooth sectioning was performed mostly in the CBCT group $(p<0.05)$, basing the decision also on the evaluation of CBCT images. The average duration of surgery was 31.01 ( \pm 16.65$)$ minutes ranging from 3 to $130 \mathrm{~min}$.

For 193 patients (51.06\%), a second-level X-ray was required. Table 3 shows the distribution of Maglione et al. radiological classes in the sample. chi-squared test show that the distribution of the radiological classes is similar between males and females $(p>0.05)$, and an ANOVA test with Tukey's post hoc test shows that the average age distribution is also similar between the classes $(p>0.05)$

Table 3. Distribution of radiologic classes according to Maglione et al. 2015, in the sample of Cone Beam Computed Tomography (CBCT) patients.

\begin{tabular}{ccccc}
\hline $\begin{array}{c}\text { CBCT } \\
\text { Radiologic } \\
\text { Classes }\end{array}$ & $\begin{array}{c}\text { Frequency in } \\
\text { CBCT Patients } \\
(\boldsymbol{n}, \boldsymbol{\%})\end{array}$ & $\begin{array}{c}\text { Frequency in } \\
\text { Males }(\boldsymbol{n}, \boldsymbol{\%})\end{array}$ & $\begin{array}{c}\text { Frequency in } \\
\text { Females }(\boldsymbol{n}, \mathbf{\%})\end{array}$ & Age (Years, SD) \\
\hline 0 & $1(0.52)$ & $0(0)$ & $1(1.01)$ & $23,-$ \\
1A & $6(3.11)$ & $4(4.25)$ & $2(2.02)$ & $31.5(12.69)$ \\
1B & $13(6.73)$ & $7(7.45)$ & $6(6.06)$ & $31.46(11.70)$ \\
2A & $2(1.03)$ & $2(2.13)$ & $0(0)$ & $34(5.65)$ \\
2B & $6(3.11)$ & $5(5.32)$ & $1(1.01)$ & $29.66(12.66)$ \\
3A & $37(19.17)$ & $19(20.21)$ & $18(18.18)$ & $25.86(7.06)$ \\
3B & $52(26.94)$ & $24(25.53)$ & $28(28.28)$ & $28.09(12.31)$ \\
4A & $20(10,36)$ & $10(10.64)$ & $10(10.1)$ & $24.75(5.71)$ \\
4B & $47(24,35)$ & $18(19.14)$ & $29(29.29)$ & $29.06(13.22)$ \\
5A & $0(0)$ & $0(0)$ & $0(0)$ & - \\
5B & $2(1.03)$ & $1(1.06)$ & $1(1.01)$ & $33.5(2.12)$ \\
6A & $3(1.55)$ & $3(3.19)$ & $0(0)$ & $30.66(0.57)$ \\
6B & $4(2.07)$ & $1(1.06)$ & $3(3.03)$ & $28(8.20)$ \\
7 & $0(0)$ & $0(0)$ & $0(0)$ & \\
\hline
\end{tabular}

Table 4 reports the distribution of the teeth, of the CBCT group, in the function of their contact with the mandibular canal. Only 29 elements $(15.10 \%)$ were not in contact with the mandibular canal, and $163(84.89 \%)$ lied in direct contact. A total of 108 mandibular canals (56.25\%) were in vestibular or apical position in respect to the tooth, $76(39.58 \%)$ were in lingual position, and $12(6.25 \%)$ run between the roots. IAN position was unknown in only one case in which canal corticalization was absent. For all the positions considered, Fisher's exact test showed that in most cases, there was a contact between IAN and the third molar (buccal or apical, $p<0.001$; lingual, $p<0.001$; interradicular, $p<0.05$ ). 
Table 4. Distribution of the elements regarding direct contact with the mandibular canal *.

\begin{tabular}{cccc}
\hline Position & $\begin{array}{c}\text { No Contact } \\
\text { IAN/Third Molar }\end{array}$ & $\begin{array}{c}\text { Contact } \\
\text { IAN/Third Molar }\end{array}$ & Total \\
\hline Buccal or apical & 19 & $89^{\mathrm{a}}$ & 108 \\
Lingual & 8 & $67^{\mathrm{a}}$ & 76 \\
Interradicular & 2 & $7^{\mathrm{b}}$ & 12 \\
Total & 29 & $163^{\mathrm{a}}$ & 192 \\
\hline
\end{tabular}

a significant difference in respect with the "no contact" group (Fisher's exact test, $p<0.001$ ); ${ }^{b}$ significant difference in respect with "No contact" group (Fisher's exact test, $p<0.05$ ); ${ }^{*}$ one tooth not classifiable for the absence of the canal corticalization (class 0 ).

Twelve patients (3.17\%) showed neurological complications following surgery. In one patient $(0.26 \%)$, sensitive impairment became permanent. 6 patients $(1.58 \%)$ suffered IAN complications, $4(1.06 \%)$ LN impairment, one patient $(0.26 \%)$ developed both IAN and $\mathrm{LN}$ paresthesia, and one subject showed LN and BN alterations. The characteristics of the patients with neurological complications are reported in Table 5.

Table 5. Characteristics of the patients who developed neurological complications.

\begin{tabular}{|c|c|c|c|c|c|c|c|c|c|c|c|c|}
\hline$n$ & Gender & Tooth & Age & $\begin{array}{l}\text { Extraction } \\
\text { Indication }\end{array}$ & $\begin{array}{l}\text { Winter } \\
\text { Classifica- } \\
\text { tion }\end{array}$ & $\begin{array}{c}\text { Pell and } \\
\text { Gregory } \\
\text { Classification }\end{array}$ & $\begin{array}{l}\text { Maglione } \\
\text { et al. Clas- } \\
\text { sification }\end{array}$ & $\begin{array}{l}\text { Anesthetic } \\
\text { Modality }\end{array}$ & $\begin{array}{l}\text { Type of } \\
\text { Surgery }\end{array}$ & $\begin{array}{c}\text { Injured } \\
\text { Nerve }\end{array}$ & $\begin{array}{c}\text { Duration of } \\
\text { Sensory } \\
\text { Disturbance }\end{array}$ & $\begin{array}{c}\text { Surgical } \\
\text { Time } \\
\text { (min) }\end{array}$ \\
\hline 1 & $\mathrm{M}$ & 48 & 28 & Periodontitis & $\mathrm{B}$ & $2-C$ & $4 \mathrm{~A}$ & Local & $\mathrm{F} / \mathrm{OS} / \mathrm{TS}$ & IAN & Permanent & 20 \\
\hline 2 & M & 38 & 35 & Periodontitis & M & $1-\mathrm{A}$ & $4 \mathrm{~B}$ & Local & F/OS/TS & IAN & Temporary & 60 \\
\hline 3 & $\mathrm{~F}$ & 48 & 55 & Neuritis & $\mathrm{D}$ & $3-C$ & $4 \mathrm{~B}$ & Local & F/OS/TS & $\mathrm{IAN}+\mathrm{LN}$ & Temporary & 45 \\
\hline 4 & $\mathrm{~F}$ & 38 & 28 & Pericoronitis & $\mathrm{B}$ & $2-B$ & $4 \mathrm{~B}$ & Local & F/OS/TS & IAN & Temporary & 40 \\
\hline 5 & $\mathrm{~F}$ & 48 & 40 & Pericoronitis & M & $2-B$ & - & Local & $\mathrm{F} / \mathrm{OS} / \mathrm{TS}$ & IAN & Temporary & 45 \\
\hline 6 & M & 48 & 55 & Pericoronitis & $\mathrm{D}$ & $2-B$ & - & Local & $\mathrm{F} / \mathrm{OS} / \mathrm{TS}$ & IAN & Temporary & 35 \\
\hline 7 & $\mathrm{~F}$ & 38 & 28 & Pericoronitis & $\mathrm{O}$ & $3-B$ & $4 \mathrm{~B}$ & Local & F/OS/TS & IAN & Temporary & 35 \\
\hline 8 & $\mathrm{~F}$ & 48 & 50 & Caries & $\mathrm{O}$ & $2-\mathrm{A}$ & - & Local & $\mathrm{F} / \mathrm{OS} / \mathrm{TS}$ & LN & Temporary & 33 \\
\hline 9 & $\mathrm{~F}$ & 48 & 26 & Pericoronitis & M & $2-B$ & - & Local & F/OS/TS & $\mathrm{LN}+\mathrm{BN}$ & Temporary & 40 \\
\hline 10 & M & 38 & 32 & Cyst & $\mathrm{B}$ & $2-C$ & $5 \mathrm{~B}$ & General & $\mathrm{F} / \mathrm{OS} / \mathrm{TS}$ & LN & Temporary & 45 \\
\hline 11 & $\mathrm{~F}$ & 38 & 23 & Pericorontis & B & $3-C$ & $4 \mathrm{~A}$ & General & $\mathrm{F} / \mathrm{OS} / \mathrm{TS}$ & $\mathrm{LN}$ & Temporary & 20 \\
\hline 12 & $\mathrm{~F}$ & 48 & 32 & Pericorontis & B & 1-A & - & Local & F/OS & LN & Temporary & 25 \\
\hline
\end{tabular}

F, flap; OS, ostectomy.; TS, tooth sectioning; B, buccal version; M, mesial version; D, distal version. IAN, inferior alveolar nerve; LN, lingual nerve; $\mathrm{BN}$, buccal nerve.

One patient out of $12(8.3 \%)$ had painful symptoms related to the IAN area.

The chi-squared test showed a statistically significant correlation between the lingual position of canals in contact with the tooth (class $4 \mathrm{~A}$ and $4 \mathrm{~B}$, according to Maglione et al.) and the development of postoperative neurological complications. This was true considering both the overall paresthesia sample $(p=0.003)$ and even more significant considering only the IAN paresthesia sample $(p=0.001)$.

A statistically significant correlation emerged between age and the development of postoperative neurological complications. chi-squared test correlated age above 25 with the neurological impairment $(p=0.003)$. Surgical operative times were also shown to be statistically significant $(p=0.0034)$ starting from 30 -min duration cutoff. Other variables as pericoronaritis $(p=0.78)$, depth of inclusion $(p=0.38)$, gender $(p=0.39)$, did not show statistical significance. Lack of canal corticalization was also not significant regarding neurological complications $(p=0.24)$.

Furthermore, the absence of a CBCT exam was not significantly correlated with an increased incidence of paresthesia $(p=0.60)$.

\section{Discussion}

The distribution of radiological classes found in the present study does not reflect the general population, in which the extraction of the third molar must be performed but represents a subpopulation in which the orthopantomography revealed an anatomical relationship between IAN and the lower third molar. This sample was per se at risk of postoperative neurological complications. 
In this sample, in approximately $85 \%$ of patients in which a 3D radiographic examination was required, the lower wisdom teeth were in direct contact with the mandibular canal. In most cases, therefore, a 3D radiographic examination appears to be justified [67].

Most mandibular canals run buccally or apically to the element, while the occurrence of the interradicular canal was rare $(6.25 \%)$, as reported in the literature $[20,21]$, probably because third molars with three or more roots or in a tilted position are rare.

The incidence of IAN-related lesions following third-molar surgery ranges between $0.17 \%$ and $8.4 \%$ in the overall population [15], or more (35\%) in selected cases in which an intimate tooth-canal relationship is known [57]. Conversely, LN injuries occurrence is considered to lie between $0.1 \%$ and $22 \%$ [15].

Nerve injury will be permanent in a variable of $0.04 \%$ to $0.7 \%$ for IAN and around $1 \%$ for LN. The persistence of clinical symptoms is related to different nerve injury patterns [1].

In the present study, $3.17 \%(n=12)$ of patients reported a neurological complication. Of these, $8.3 \%$ ( $n=1 ; 0.26 \%$ of the total sample) reported an irreversible impairment.

Results showed that the lingual position of the mandibular canal was identified as a significant factor for the development of neurological complications, but only in $4 \mathrm{~A}$ and $4 \mathrm{~B}$ subclasses (direct contact with the tooth). Lingual position of the canal, even more, if the latter is placed more coronally, could lead to a compression of the nerve during the tooth elevation procedures as the third molar is mainly approached mesial-buccally and tends to follow a distal-lingual path to leave the socket. According to these results, the authors suggest that coronectomy should be performed before tooth dislocation.

When we considered the 25-year cutoff, as reported in the literature, patient age was a significant factor for postoperative neurological disturbances $[15,16,48]$. This could be related to a different bone biodynamic and/or to different nerve injury coping patterns at a young age.

Surgical operative times were significantly related to the incidence of neurological complications. It is not clear if the time factor affects postoperative parameters such as edema, or if it is directly proportional to the surgery challenge, or both. However, in this sample, an extended surgery duration can be considered a negative prognostic indicator regarding nerve injuries. Moreover, one of the factors reported to affect surgical time is intraoperative exposure of the IAN [68]. This occurrence, according to some authors, is also connected with an increased risk of postoperative neurological complications [15].

The relationship between the availability of CBTC images and the development of neurological disturbances was not significant. This is consistent with other works $[38,43,69]$. However, it is clear that radiographic signs, identified on 3D X-ray examination, can provide valuable information, especially in borderline cases such as aberrant positions of the canal, associated pathological structures that shift canal position from the original site, or interradicular mandibular canals. In all these cases, 3D X-ray examination can provide valuable indications for planning the surgery and reduce the risks associated with the extraction of impacted lower third molars $[67,70]$.

The absence of the canal corticalization was not statistically significant. Probably during the surgical maneuvers, a thin cortical bone sheet, like mandibular canal one, can offer very little resistance to compressive crushing elevation forces.

Operator experience was reported to be significant in some works [12,50,71], but this variable was not considered in this study as all surgeons had more than five years of experience.

This study has potential limitations. The first concern is about the limited sample size, resulting in a rare frequency of nerve injuries. Another concern could be about the subjective expression and heterogeneous clinical presentation of nerve lesions, resulting in the need to rely on patient descriptions of symptoms. In this sense, further studies are encouraged. 


\section{Conclusions}

Most of the considered third molars belonged to class 3 according to Maglione et al. classification.

Despite the relative rarity of neurological complications, Maglione et al. class $4 \mathrm{~A}$ or $4 \mathrm{~B}$, patients over 25 years old and an extended surgical time (greater than $30 \mathrm{~min}$ ) can be considered as unfavorable prognostic indicators for the development of sensitivity impairments within the population considered. On the contrary, previous pericoronaritis, the depth of the inclusion, and the gender of the patient determine less important risk factors for postoperative neurological complications.

Author Contributions: S.B. made the literature search and wrote the manuscript, C.G. contributed to design and implement the research analyzing the results, F.C. and L.B. designed the study and revised the manuscript, D.P. analyzed the data and performed the statistical analysis, M.M. directed the project and revised the manuscript. All the authors approved the final version of the manuscript. All authors have read and agreed to the published version of the manuscript.

Funding: This research did not receive any specific grant from funding agencies in the public, commercial, or not-for-profit sectors.

Institutional Review Board Statement: This study has been reviewed and approved by the Ethics Committee of the University of Trieste (UNITS 7/2016) as written in the text (verbal n. $70 \mathrm{dd}$ 18.04.2016).

Informed Consent Statement: Informed consent was obtained from all subjects involved in the study. Data Availability Statement: Not applicable.

Conflicts of Interest: No potential conflict of interest to declare.

\section{References}

1. Loescher, A.; Smith, K.; Robinson, P.P. Nerve damage and third molar removal. Dent. Update 2003, 30, 375-382. [CrossRef] [PubMed]

2. Pippi, R.; Santoro, M.; D'Ambrosio, F. Accuracy of cone-beam computed tomography in defining spatial relationships between third molar roots and inferior alveolar nerve. Eur. J. Dent. 2016, 10, 454-458. [CrossRef]

3. Terumitsu, M.; Matsuzawa, H.; Seo, K.; Watanabe, M.; Kurata, S.; Suda, A.; Nakada, T. High-contrast high-resolution imaging of posttraumatic mandibular nerve by 3DAC-PROPELLER magnetic resonance imaging: Correlation with the severity of sensory disturbance. Oral Surg. Oral Med. Oral Pathol. Oral Radiol. 2017, 124, 85-94. [CrossRef] [PubMed]

4. Dias, G.; De Silva, R.; Shah, T.; Sim, E.; Song, N.; Colombage, S.; Cornwall, J. Multivariate assessment of site of lingual nerve. Br. J. Oral Maxillofac. Surg. 2015, 53, 347-351. [CrossRef] [PubMed]

5. Behnia, H.; Kheradvar, A.; Shahrokhi, M. An anatomic study of the lingual nerve in the third molar region. J. Oral Maxillofac. Surg. 2000, 58, 649-653. [CrossRef]

6. Miloro, M.; Halkias, L.E.; Slone, H.; Chakeres, D.W. Assessment of the lingual nerve in the third molar region using magnetic resonance imaging. J. Oral Maxillofac. Surg. 1997, 55, 134-137. [CrossRef]

7. Kiesselbach, J.E.; Chamberlain, J.G. Clinical and anatomic observations on the relationship of the lingual nerve to the mandibu-lar third molar region. J. Oral Maxillofac. Surg. 1984, 42, 565-567. [CrossRef]

8. Hölzle, F.W.; Wolff, K.-D. Anatomic position of the lingual nerve in the mandibular third molar region with special considera-tion of an atrophied mandibular crest: An anatomical study. Int. J. Oral Maxillofac. Surg. 2001, 30, 333-338. [CrossRef]

9. Benninger, B.; Kloenne, J.; Horn, J.L. Clinical anatomy of the lingual nerve and identification with ultrasonography. Br. J. Oral Maxillofac. Surg. 2013, 51, 541-544. [CrossRef] [PubMed]

10. Hillerup, S.; Stoltze, K. Lingual nerve injury in third molar surgery I. Observations on recovery of sensation with spontaneous healing. Int. J. Oral Maxillofac. Surg. 2007, 36, 884-889. [CrossRef]

11. Fielding, A.F.; Rachiele, D.P.; Frazier, G. Lingual nerve paresthesia following third molar surgery: A retrospective clinical study. Oral Surg. Oral Med. Oral Pathol. Oral Radiol. Endod. 1997, 84, 345-348. [CrossRef]

12. Cheung, L.; Leung, Y.; Chow, L.; Wong, M.; Chan, E.; Fok, Y. Incidence of neurosensory deficits and recovery after lower third molar surgery: A prospective clinical study of 4338 cases. Int. J. Oral Maxillofac. Surg. 2010, 39, 320-326. [CrossRef] [PubMed]

13. Lydiatt, D.D. Litigation and the lingual nerve. J. Oral Maxillofac. Surg. 2003, 61, 197-200. [CrossRef] [PubMed]

14. Pippi, R.; Spota, A.; Santoro, M. Prevention of Lingual Nerve Injury in Third Molar Surgery: Literature Review. J. Oral Maxillofac. Surg. 2017, 75, 890-900. [CrossRef]

15. Leung, Y.; Cheung, L. Risk factors of neurosensory deficits in lower third molar surgery: A literature review of prospective studies. Int. J. Oral Maxillofac. Surg. 2011, 40,1-10. [CrossRef] [PubMed] 
16. Jerjes, W.; Upile, T.; Shah, P.; Nhembe, F.; Gudka, D.; Kafas, P.; McCarthy, E.; Abbas, S.; Patel, S.; Hamdoon, Z.; et al. Risk factors associated with injury to the in-ferior alveolar and lingual nerves following third molar surgery-revisited. Oral Surg. Oral Med. Oral Pathol. Oral Radiol. 2010, 109, 335-345. [CrossRef]

17. Tiwari, A.K.; Lata, J. Incidence of lingual nerve paraesthesia following mandibular third molar surgery. Natl. J. Maxillofac. Surg. 2011, 2, 137-140. [CrossRef]

18. Babu, H.S.C.; Reddy, P.B.; Pattathan, R.K.B.; Desai, R.; Shubha, A.B. Factors influencing lingual nerve paraesthesia following third molar surgery: A prospective clinical study. J. Maxillofac. Oral Surg. 2013, 12, 168-172.

19. Korkmaz, Y.; Kayıpmaz, S.; Senel, F.; Atasoy, K.; Gumrukcu, Z. Does additional cone beam computed tomography decrease the risk of inferior alveolar nerve injury in high-risk cases undergoing third molar surgery? Does CBCT decrease the risk of IAN injury? Int. J. Oral Maxillofac. Surg. 2017, 46, 628-635. [CrossRef]

20. Maegawa, H.; Sano, K.; Kitagawa, Y.; Ogasawara, T.; Miyauchi, K.; Sekine, J.; Inokuchi, T. Preoperative assessment of the relation-ship between the mandibular third molar and the mandibular canal by axial computed tomography with coronal and sagittal reconstruction. Oral Surg. Oral Med. Oral Pathol. Oral Radiol. Endod. 2003, 96, 639-646. [CrossRef]

21. Wang, W.-Q.; Chen, M.Y.C.; Huang, H.-L.; Fuh, L.-J.; Tsai, M.-T.; Hsu, J.-T. New quantitative classification of the anatomical relation-ship between impacted third molars and the inferior alveolar nerve. BMC Med. Imaging 2015, 15, 59. [CrossRef] [PubMed]

22. Maglione, M.; Costantinides, F.; Bazzocchi, G. Classification of impacted mandibular third molars on cone-beam CT images. J. Clin. Exp. Dent. 2015, 7, e224-e231. [CrossRef] [PubMed]

23. Tantanapornkul, W.; Okouchi, K.; Fujiwara, Y.; Yamashiro, M.; Maruoka, Y.; Ohbayashi, N.; Kurabayashi, T. A comparative study of cone-beam computed tomography and conventional panoramic radiography in assessing the topographic relationship between the mandibular canal and impacted third molars. Oral Surg. Oral Med. Oral Pathol. Oral Radiol. Endod. 2007, 103, 253-259. [CrossRef]

24. Ueda, M.; Nakamori, K.; Shiratori, K.; Igarashi, T.; Sasaki, T.; Anbo, N.; Kaneko, T.; Suzuki, N.; Dehari, H.; Sonoda, T.; et al. Clinical Significance of Computed Tomographic Assessment and Anatomic Features of the Inferior Alveolar Canal as Risk Factors for Injury of the Inferior Alveolar Nerve at Third Molar Surgery. J. Oral Maxillofac. Surg. 2012, 70, 514-520. [CrossRef] [PubMed]

25. Monaco, G.; Montevecchi, M.; Bonetti, G.A.; Gatto, M.R.A.; Checchi, L. Reliability of panoramic radiography in evaluating the topographic relationship between the mandibular canal and impacted third molars. J. Am. Dent. Assoc. 2004, 135, 312-318. [CrossRef]

26. Öhman, A.; Kivijärvi, K.; Blombäck, U.; Flygare, L. Pre-operative radiographic evaluation of lower third molars with computed tomography. Dentomaxillofacial Radiol. 2006, 35, 30-35. [CrossRef] [PubMed]

27. Ghaeminia, H.; Meijer, G.; Soehardi, A.; Borstlap, W.; Mulder, J.; Bergé, S. Position of the impacted third molar in relation to the mandibular canal. Diagnostic accuracy of cone beam computed tomography compared with panoramic radiography. Int. J. Oral Maxillofac. Surg. 2009, 38, 964-971. [CrossRef]

28. Zandi, M.; Shokri, A.; Malekzadeh, H.; Amini, P.; Shafiey, P. Evaluation of third molar development and its relation to chronological age: A panoramic radiographic study. Oral Maxillofac. Surg. 2015, 19, 183-189. [CrossRef]

29. Bell, G.W.; Rodgers, J.M.; Grime, R.J.; Edwards, K.L.; Hahn, M.R.; Dorman, M.L.; Keen, W.D.; Stewart, D.J.; Hampton, N. The accuracy of dental panoramic tomographs in determining the root morphology of mandibular third molar teeth before surgery. Oral Surg. Oral Med. Oral Pathol. Oral Radiol. Endod. 2003, 95, 119-125. [CrossRef] [PubMed]

30. Suomalainen, A.; Ventä, I.; Mattila, M.; Turtola, L.; Vehmas, T.; Peltola, J.S. Reliability of CBCT and other radiographic methods in preoperative evaluation of lower third molars. Oral Surg. Oral Med. Oral Pathol. Oral Radiol. Endod. 2010, 109, 276-284. [CrossRef]

31. Szalma, J.; Lempel, E.; Jeges, S.; Szabó, G.; Olasz, L. The prognostic value of panoramic radiography of inferior alveolar nerve damage after mandibular third molar removal: Retrospective study of 400 cases. Oral Surg. Oral Med. Oral Pathol. Oral Radiol. Endod. 2010, 109, 294-302. [CrossRef] [PubMed]

32. Valmaseda-Castellón, E.; Berini-Aytés, L.; Gay-Escoda, C. Inferior alveolar nerve damage after lower third molar surgical ex-traction: A prospective study of 1117 surgical extractions. Oral Surg. Oral Med. Oral Pathol. Oral Radiol. Endod. 2001, 92, 377-383. [CrossRef] [PubMed]

33. Atieh, M.A. Diagnostic Accuracy of Panoramic Radiography in Determining Relationship Between Inferior Alveolar Nerve and Mandibular Third Molar. J. Oral Maxillofac. Surg. 2010, 68, 74-82. [CrossRef]

34. Rood, J.; Shehab, B.N. The radiological prediction of inferior alveolar nerve injury during third molar surgery. Br. J. Oral Maxillofac. Surg. 1990, 28, 20-25. [CrossRef]

35. Sedaghatfar, M.; August, M.A.; Dodson, T.B. Panoramic radiographic findings as predictors of inferior alveolar nerve exposure following third molar extraction. J. Oral Maxillofac. Surg. 2005, 63, 3-7. [CrossRef]

36. De Melo Albert, D.G.; Gomes, A.C.A.; do Egito Vasconcelos, B.C.; de Oliveira e Silva, E.D.; Holanda, G.Z. Comparison of orthopan-tomographs and conventional tomography images for assessing the relationship between impacted lower third molars and the mandibular canal. J. Oral Maxillofac. Surg. 2006, 64, 1030-1037. [CrossRef] [PubMed]

37. Kim, J.-W.; Cha, I.-H.; Kim, S.-J.; Kim, M.-R. Which Risk Factors Are Associated With Neurosensory Deficits of Inferior Alveolar Nerve After Mandibular Third Molar Extraction? J. Oral Maxillofac. Surg. 2012, 70, 2508-2514. [CrossRef]

38. Matzen, L.H.; Wenzel, A. Efficacy of CBCT for assessment of impacted mandibular third molars: A review-Based on a hierar-chical model of evidence. Dento. Radiol. 2015, 44, 20140189. [CrossRef] [PubMed] 
39. Susarla, S.M.; Sidhu, H.K.; Avery, L.L.; Dodson, T.B. Does computed tomographic assessment of inferior alveolar canal cortical in-tegrity predict nerve exposure during third molar surgery? J. Oral Maxillofac. Surg. 2010, 68, 1296-1303. [CrossRef]

40. Nakamori, K.; Tomihara, K.; Noguchi, M. Clinical significance of computed tomography assessment for third molar surgery. World J. Radiol. 2014, 6, 417-423. [CrossRef]

41. Park, W.; Choi, J.-W.; Kim, J.-Y.; Kim, B.-C.; Kim, H.J.; Lee, S.-H. Cortical integrity of the inferior alveolar canal as a predictor of par-esthesia after third-molar extraction. J. Am. Dent. Assoc. 2010, 141, 271-278. [CrossRef] [PubMed]

42. Nakayama, K.; Nonoyama, M.; Takaki, Y.; Kagawa, T.; Yuasa, K.; Izumi, K.; Ozeki, S.; Ikebe, T. Assessment of the relationship be-tween impacted mandibular third molars and inferior alveolar nerve with dental 3-dimensional computed tomography. $J$. Oral Maxillofac. Surg. 2009, 67, 2587-2591. [CrossRef] [PubMed]

43. Guerrero, M.E.; Botetano, R.; Beltran, J.; Horner, K.; Jacobs, R. Can preoperative imaging help to predict postoperative outcome after wisdom tooth removal? A randomized controlled trial using panoramic radiography versus cone-beam CT. Clin. Oral Investig. 2014, 18, 335-342. [CrossRef]

44. Wang, D.; Lin, T.; Wang, Y.; Sun, C.; Yang, L.; Jiang, H.; Cheng, J. Radiographic features of anatomic relationship between impacted third molar and inferior alveolar canal on coronal CBCT images: Risk factors for nerve injury after tooth extraction. Arch. Med Sci. 2018, 14, 532-540. [CrossRef]

45. Xu, G.-Z.; Yang, C.; Fan, X.-D.; Yu, C.-Q.; Cai, X.-Y.; Wang, Y.; He, D. Anatomic relationship between impacted third mandibular molar and the mandibular canal as the risk factor of inferior alveolar nerve injury. Br. J. Oral Maxillofac. Surg. 2013, 51, e215-e219. [CrossRef] [PubMed]

46. Meyer, R.A.; Bagheri, S.C. Nerve Injuries from Mandibular Third Molar Removal. Atlas Oral Maxillofac. Surg. Clin. 2011, 19, 63-78. [CrossRef]

47. Meyer, R.A.; Bagheri, S.C. Clinical Evaluation of Peripheral Trigeminal Nerve Injuries. Atlas Oral Maxillofac. Surg. Clin. 2011, 19, 15-33. [CrossRef]

48. Barone, R.; Clauser, C.; Testori, T.; Del Fabbro, M. Self-assessed neurological disturbances after surgical removal of impacted lower third molar: A pragmatic prospective study on 423 surgical extractions in 247 consecutive patients. Clin. Oral Investig. 2018, 23, 3257-3265. [CrossRef]

49. Blondeau, F.; Daniel, N.G. Extraction of impacted mandibular third molars: Postoperative complications and their risk factors. J. Can. Dent. Assoc. 2007, 73, 325-325.e6.

50. Bataineh, A.B. Sensory nerve impairment following mandibular third molar surgery. J. Oral Maxillofac. Surg. 2001, 59, 1012-1017. [CrossRef] [PubMed]

51. Genú, P.R.; Vasconcelos, B.C.E. Influence of the tooth section technique in alveolar nerve damage after surgery of impacted low-er third molars. Int. J. Oral Maxillofac. Surg. 2008, 37, 923-928. [CrossRef] [PubMed]

52. Brann, C.R.; Brickley, M.R.; Shepherd, J. Factors influencing nerve damage during lower third molar surgery. Br. Dent. J. 1999, 186, 514-516. [CrossRef]

53. Costantinides, F.; Biasotto, M.; Maglione, M.; Di Lenarda, R. Local vs. general anaesthesia in the development of neurosensory disturbances after mandibular third molars extraction: A retrospective study of 534 cases. Med. Oral Patol. Oral Cir. Bucal 2016, 21, e724-e730. [CrossRef]

54. Takezawa, K.; Ghabriel, M.; Townsend, G. The course and distribution of the buccal nerve: Clinical relevance in dentistry. Aust. Dent. J. 2018, 63, 66-71. [CrossRef]

55. Alvira-González, J.; Gay-Escoda, C. Sensory disturbances of buccal and lingual nerve by muscle compression: A case report and review of the literature. J. Clin. Exp. Dent. 2015, 8, e93-e96. [CrossRef] [PubMed]

56. Akadiri, O.A.; Fasola, A.O.; Arotiba, J.T. Incidence and risk factors for nerve injuries in mandibular third molar surgery. Niger. J. Med. 2010, 18, 402-408. [CrossRef]

57. Jhamb, A.; Dolas, R.S.; Pandilwar, P.K.; Mohanty, S. Comparative efficacy of spiral computed tomography and orthopantomography in preoperative detection of relation of inferior alveolar neurovascular bundle to the impacted mandibular third molar. $J$. Oral Maxillofac. Surg. 2009, 67, 58-66. [CrossRef]

58. Qi, W.; Lei, J.; Liu, Y.N.; Li, J.N.; Pan, J.; Yu, G.Y. Evaluating the risk of post-extraction inferior alveolar nerve injury through the rel-ative position of the lower third molar root and inferior alveolar canal. Int. J. Oral Maxillofac. Surg. 2019, 48, 1577-1583. [CrossRef] [PubMed]

59. Robert, R.C.; Bacchetti, P.; Pogrel, M.A. Frequency of Trigeminal Nerve Injuries Following Third Molar Removal. J. Oral. Maxillofac. Surg. 2005, 63, 732-735. [CrossRef] [PubMed]

60. La Monaca, G.; Vozza, I.; Giardino, R.; Annibali, S.; Pranno, N.; Cristalli, M.P. Prevention of neurological injuries during mandibu-lar third molar surgery: Technical notes. Ann. Stomatol. 2017, 8, 45-52. [CrossRef]

61. Menziletoglu, D.; Tassoker, M.; Kubilay-Isik, B.; Esen, A. The assesment of relationship between the angulation of impacted man-dibular third molar teeth and the thickness of lingual bone: A prospective clinical study. Med. Oral Patol. Oral Cir. Bucal 2019, 1, e130-e135.

62. Pitros, P.; O'Connor, N.; Tryfonos, A.; Lopes, V. A systematic review of the complications of high-risk third molar removal and coronectomy: Development of a decision tree model and preliminary health economic analysis to assist in treatment planning. $\mathrm{Br}$. J. Oral Maxillofac. Surg. 2020, 58, e16-e24. [CrossRef]

63. Pogrel, M.; Goldman, K.E. Lingual flap retraction for third molar removal. J. Oral Maxillofac. Surg. 2004, 62, 1125-1130. [CrossRef] 
64. Greenwood, M.; Langton, S.; Rood, J. A comparison of broad and narrow retractors for lingual nerve protection during lower third molar surgery. Br. J. Oral Maxillofac. Surg. 1994, 32, 114-117. [CrossRef]

65. European Commission. Radiation Protection No. 172. Cone Beam CT for Dental and Maxillofacial Radiology. Evidence Based Guidelines. Official Website of the European Union. 2012. Available online: https://op.europa.eu/en/publication-detail/-/ publication/ec5936c7-5a29-4a93-9b3a-01a5d78d7b2e (accessed on 15 January 2019). [CrossRef]

66. Wilson, W.; Taubert, K.A.; Gewitz, M.; Lockhart, P.B.; Baddour, L.M.; Levison, M.; Bolger, A.; Cabell, C.H.; Takahashi, M.; Baltimore, R.S.; et al. Prevention of infective endocarditis: Guidelines from the American Heart Association: A guideline from the American Heart Association Rheumatic Fever, Endocarditis and Kawasaki Disease Com-mittee, Council on Cardiovascular Disease in the Young, and the Council on Clinical Cardiology, Council on Cardiovascular Surgery and Anesthesia, and the Quality of Care and Outcomes Research Interdisciplinary Working Group. J. Am. Dent. Assoc. 2008, 139, 3S-24S. [PubMed]

67. Bozkurt, P.; Görürgöz, C. Detecting direct inferior alveolar nerve-Third molar contact and canal decorticalization by cone-beam computed tomography to predict postoperative sensory impairment. J. Stomatol. Oral Maxillofac. Surg. 2020, 121, 259-263. [CrossRef]

68. Benediktsdóttir, I.S.; Wenzel, A.; Petersen, J.K.; Hintze, H. Mandibular third molar removal: Risk indicators for extended operation time, postoperative pain, and complications. Oral Surg. Oral Med. Oral Pathol. Oral Radiol. Endod. 2004, 97, 438-446. [CrossRef] [PubMed]

69. De Telles-Araújo, G.T.; Peralta-Mamani, M.; Caminha, R.D.G.; de Moraes-da-Silva, A.F.; Rubira, C.M.F.; Honório, H.M.; RubiraBullen, I.R.F. CBCT does not reduce neurosensory disturbances after third molar removal compared to panoramic ra-diography: A systematic review and meta-analysis. Clin. Oral Investig. 2020, 24, 1137-1149. [CrossRef] [PubMed]

70. Al Ali, S.; Jaber, M. Correlation of panoramic high-risk markers with the cone beam CT findings in the preoperative assessment of the mandibular third molars. J. Dent. Sci. 2020, 15, 75-83. [CrossRef]

71. Goldberg, M.H. Frequency of trigeminal nerve injuries following third molar removal. J. Oral Maxillofac. Surg. 2005, 63, 1783. [CrossRef] 